\section{Few Bouquets for BEA}

THe committee of inquiry set up in July to examine the civil air transport industry in Britain was sent on its way last week by a report sharply critical of civil aviation in Britain. The report came from the Select Committee on the Nationalized Industries, which spent the last session of Parliament examining British European Airways. Judged by the opinion some people have of BEA, the report was comparatively mild, but there were distinct undertones of criticism. "Whether or not BEA have been slow to change, Your Committee are satisfied that they are changing now . . . It would be churlish indeed if Your Committee's only reaction to new developments were to ask why they were not introduced before... . They congratulate BEA on introducing the new methods, and accept them as indications that BEA's management is not at present static or lacking in ideas."

But BEA was not alone in being criticized. In particular, the committee commented on the division of function by which the Ministry of Technology is responsible for sponsoring new aircraft, while the Board of Trade administers civil aviation. As a result, the report says, the formal channels provide for BEA to have contact only with the Board of Trade, while the manufacturers have contact only with the Ministry of Technology. This tortuous link makes it harder for BEA to be heard when decisions are being made at the Ministry of Technology, particularly when the ministry is arguing the specification of the European airbus, which BEA will be expected to buy.

On the other hand, BEA should not have too much say in the design of aircraft. "Tailor-made" aircraft, like the Trident, were difficult to sell abroad - although the Viscount, another BEA aircraft, had been very successful. Hawker-Siddeley, who aoreed to change the specification of the Trident to suit BEA, had regretted it. This part of the report has an important bearing on BEA's current campaign to get approval for the building of the BAC 2-11. BAC first put the idea forward in February 1967, and immediately BEA put in an application for sanction to buy it. At the same time, the airbus negotiations were in progress with France and Germany. If BEA was forced to operate the Trident 3B, another possibility, it would need government compensation (a poor comment on an aircraft designed specifically for BEA's own needs), and if it was obliged to operate with VC $10 \mathrm{~s}$, it would need "enormous" compensation. There the matter stands. BEA is still hopeful of getting the BAC 2-11, and the Government is still committed to the airbus, although Lufthansa, the West German national airline, seems to be having doubts.

The committee was rather more cheerful about BEA's financial record. In the five years from 1963-4, BEA will have reached its target set in 1963 , and the committee welcomes this. As for licensing, the committee believes that the Air Transport Licensing Board, set up to grant licences to independent airlines, has become no more than a bodv from which to make appeals to the Board of Trade. The airlines themselves, the committee says, should be allowed to set their own fares, subject, if necessary, to a reference to the Prices and Incomes Board. Without its licensing or farefixing function, the ATLB would become only a consumers' council. The committee did not think that a sufficient justification for its continued existence; it should be wound up.

\section{Ceramic Mirror at Siding Spring}

A $£ 240,000$ contract has been placed with OwensIllinois of Toledo, Ohio, for the mirror blank for the 150 inch Anglo-Australian telescope which is to be constructed at Siding Spring Mountain in New South Wales. The order was placed by the Science Research Council, acting on joint Anglo-Australian behalf, and follows a decision taken at the first meeting of the Joint Policy Committee in August. The fifteen ton blank, to be delivered in about twelve months time, will be made of a glass ceramic material called 'Cervit'.

'Cervit' materials are produced from glasses of a special composition which are melted and formed in a manner similar to that used for conventional glasses. After these special glasses have been produced in the desired shape, they are subjected to a high temperature heat treatment during which the glass is gradually converted into a micro-crystalline ceramic material through the growth of crystals: the final product is homogeneous. By controlling nucleation and crystal growth, it is possible to produce very small and precisely controlled crystal sizes. Certain selected elements such as aluminium and lithium are incorporated into the crystal lattice, thus enabling the properties of the crystallized glass to be altered so that the expansion coefficient is reduced to very near zero and so that the change in expansion coefficient with temperature remains small over a wide temperature range. The telescopic mirror blank has adequate transparency for examination of defects within the blank and also has excellent polishing qualities. Furthermore, this mirror blank material has a higher thermal conductivity than fused silica and is more dense. The material is also considered stiffer than fused silica and should therefore display less sag across large edgesupported sections than the same shape made of fused silica. The main advantage, however, of a blank of this type is that it can be made in a mould in one piece.

Construction of the 150 inch telescope will take about six years. The capital and recurrent cost of the telescope, which is intended for the equal use of UK and Australian astronomers, will be shared equally by the two governments.

\section{New Electrical Giant}

Mr ARnocD Weinstock has just managed to hang on to his reputation as one of Britain's more successful businessmen. Mr Weinstock is managing director of the General Electric Company, which last week took over Associated Electrical Industries after a brisk battle. But $\mathrm{Mr}$ Weinstock was twice forced to raise his offer, and AEI was able to put up an unexpectedly vigorous defence. After it was all over, things became very chummy, and Mr. Weinstock asked three AEI directors to join the board of the new company. Only Lord Beeching, called in by AEI as a sort of managerial deus ex machina, was left without work. But he is a deputy chairman of Imperial Chemical Industries, which should be enough to keep him happy until something better comes along.

It is tempting to see the takeover as a coming together of opposites-GEC sleek but technically suspect, 
AEI engineers par excellence, clumsily managed. Neither company, of course, would accept more than one of these generalizations. The new company will be among the giants of the international electricity industry, although there are several in Europe larger. The Dutch Philips group, for example, is more than half as large again as GEC/AEI in terms of turnover. In the United States, there are five larger companies, headed by General Electric (USA) - no relation to GEC-with a staggering turnover of $£ 7,239$ million last year, against $£ 445$ million from GEC/AEI. In Britain, only the joint English Electric/Elliott Automation group comes anywhere near the new groupits turnover last year was $£ 334$ million.

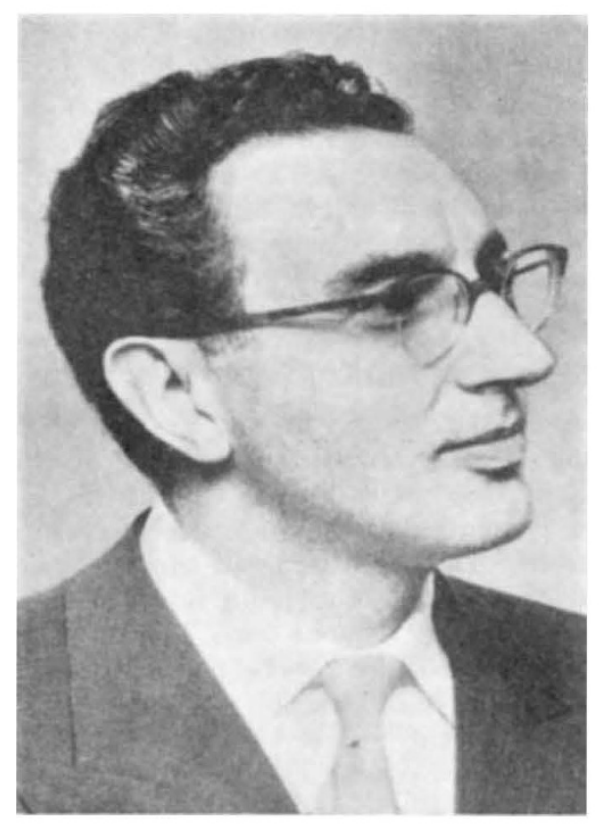

Mr Weinstock; still cheerful.

There are good reasons for hoping that the size of the new group will bring dividends. Certainly, shareholders will be hoping so, for after the confident predictions of both sides during the battle anything less than complete success is going to feel like failure. Both companies are untidy conglomerates, spreading their activities over a wide range, although GEC opted out of the heavy end of the business several years ago. One of the problems will be deciding what to do with AEI's enormous cable interests, which make up 25 per cent of the company. In other fields the merging of the two companies will be more like a normal process of rationalization, at which $\mathrm{Mr}$ Weinstock has shown himself adept. Telecommunications, for example, is ripe for brisk reorganization, and it looks as if AEI's investment in rather dated Strowger electro-mechanical exchanges-which the GPO still needs-will fit in nicely with GEC's work on smaller electronic exchanges. In transistors and semiconductors GEC has a minority interest in Associated Semiconductor Manufacturers (with Mullard) and AEI runs a joint company with Thorn. Apart from this, the companies have substantial interests in radar, automation and process control, transformers and switchgear and domestic appliances.
As befits companies in such advanced fields, both run extensive research activities (see Nature, 216, 8: 1967). These will no doubt feel the effects of rationalization too, but this week Mr Weinstock had nothing to say. The electronics and telecommunications interests may well offer the best chance of saving money by integrating research, but it is doubtful whether anything has been decided yet.

\section{Small Change on Degrees \\ from our Oxford Correspondent}

LAST week, Congregation at Oxford resolved, by a narrow margin of votes, to change the university's somewhat anomalous mode of classifying BAs. At nearly all the other universities of Britain, degrees are divided into three classes, the best and worst 10 per cent of students receiving firsts and thirds, and the intermediate 80 per cent being subdivided into upper and lower divisions. At Oxford, four classes have been awarded. Last year, the proportion of firsts was the same as in other universities, at 10 per cent. But there were fewer seconds ( 60 per cent) and far more thirds (28 per cent). Fourths are rarely awarded, and Congregation voted unanimously to abolish the class.

So what distinguishes the Oxford system is the large size of the third class and the lack of subdivision of the second. The proposers of the resolution before Congregation claimed that some students who received thirds at Oxford, and thereby are financially penalized in certain professions, would have received lower second class degrees elsewhere. This may possibly be true, though account should be taken that few undergraduates drop out of Oxford, while at some universities large numbers of students leave who would otherwise go on to swell the numbers of the third class. But if it is true that an Oxford third could have been a London lower second, the remedy is simple: award more seconds.

The argument for the division of the second class is that those awarded a second vary in ability from the borderline firsts to those who narrowly managed to avoid thirds; that, in fact, the class designates everyone except the very best and the very worst, and is meaningless as a classification. But the nature of the normal curve is such that it is far more difficult to judge fairly who is just above the average than to distinguish the very best and very worst students from the rest. There is also the question of postgraduate studies. Whether or not a student can stay on for a postoraduate course depends on the availability of grants; if he has a first. there is no problem; if he has a second, then the matter will rest on his tutor's recommendation and that of his head of department. So the really important classification is not a formal one. Those few employers, notably the Civil Service Commissioners, who draw a distinction between good and bad seconds, can always be informed of the nature of a candidate's degree by his tutor.

Nevertheless, by 101 votes to 99 , with a number of abstentions, Congregation has decided to change the degree classes - a narrow vote on a decision that will alter little; still, Oxford may have cause to regret it. Flexibility, by which is meant indeterminacy, is adduced in defence of Oxford's various institutions quite as often as "democracy", and with as little justification in most cases. But in the degree arrangements, perhaps. flexibility worked. 